\title{
Sağlık Bilimleri Fakültesi Öğrencilerinde Genel Özyeterliliğin Gelişmeleri Kaçırma Korkusu Üzerine Etkisi
}

DOI: 10.26466/opus.595661

\author{
Pınar Erdoğan* - $\underline{\text { Yasemin SŞanlı }}{ }^{* *}$ \\ ${ }^{*}$ Dr. Öğr. Üyesi, Karamanoğlu Mehmetbey Üniversitesi, UBYO, Karaman/Türkiye \\ E-Posta: pinarayturk@hotmail.com ORCID: 0000-0000-7817-1342 \\ **Dr. Öğr. Üyesi, Karamanoğlu Mehmetbey Üni., Sağlık Hizmetleri Fakültesi, Karaman/Türkiye \\ E-Posta: yaseminsanli@kmu.edu.tr ORCID: 0000-0001-9169-0577
}

Öz

Bu çalışmada üniversite öğrencilerinin genel özyeterlilik düzeyleri ile gelişmeleri kaçırma korkuları arasındaki ilişki incelenmiştir. Günümüzde akıllı telefon kullanımının artmasıyla birlikte özellikle üniversite gençlerinin yoğun ilgi gösterdiği sosyal medya kullanımı da artarak "Gelişmeleri Kaçırma Korkusu (FoMO)" adı verilen yeni bir olgunun ortaya çımasına neden olmuştur. Araştırmada amaç sağlık bilimleri fakültesine kayıtl olan öğrencilerin genel özyeterlilik düzeylerinin FoMO düzeyleri üzerinde anlamlı bir etkisinin olup olmadığının belirlenmesidir. Tanımlayıcı nitelikte olan çalışmanın evrenini 2018-2019 Eğitim-öğretim Yılı Bahar Dönemi'nde Karamanoğlu Mehmetbey Üniversitesi Sağllk Bilimleri Fakültesi'nde öğrenim gören 450 öğrenci oluşturmaktadır. Örneklemini ise, rastgele yöntemle seçilen farklı bölüm ve sinıflarda öğrenim gören 346 öğrenci oluşturmaktadır. Veriler SosyoDemografik Soru Formu, Genel Öz-yeterlilik Ölçeği ve FoMO (Sosyal Ortamlarda Gelişmeleri Kaçırma Korkusu) Ölçeği kullanılarak toplanılmıştır. Verilerin değerlendirilmesi, SPSS 22.00 paket programında korelasyon, regresyon, kullanılarak yapılmıştır. Araştırma sonucunda öz yeterlilik ile FoMO arasında negatif ilişki bulgulanmıştır. Bu bağlamda özyeterlilik seviyesi yüksek olan öğrencilerin daha düşük düzeyde FoMO yaşayacă̆ı şeklinde yorumlanabilir.

Anahtar Kelimeler: Sosyal Medya, Özyeterlilik, Kaçırma Korkusu 


\title{
The Effects of General Self-Efficacy on Fear of Mising Out of Faculty of Health Sciences Students
}

*

\begin{abstract}
In this study, the relationship between university students' general self-efficacy levels and fear of missing out (FoMO) were studied. Today, with the increase in the use of smart phones, especially the use of social media, which attracted the attention of university young people, also increased, leading to the emergence of a new phenomenon called FoMO (FoMO). The aim of the study is to determine whether the of students enrolled in the faculty of health sciences have a significant effect on FoMO levels. The universe of this descriptive study consists of 450 students studying at the Faculty of Health Sciences of Karamanoğlu Mehmetbey University in the Spring Semester of 2018-2019 Academic Year. The sample consisted of 346 students studying in different departments and classes randomly selected. Data were collected using Sociodemographic Questionnaire, General Self-Efficacy Scale and FoMO (Fear of Missing Developments in Social Environments) Scale. In the evaluation of the data, correlation, regression, were used in SPSS 22.00 package program. As a result of the research, a negative correlation was found between self-efficacy and FoMO. In this context, it can be interpreted that students with higher selfefficacy levels will experience a lower level of FoMO.
\end{abstract}

Keywords: Social Media, Self-Efficacy, FoMO 


\section{Giriş}

İnsanların yaşamlarında karşılaştıkları sorunların üstesinden gelme şeklini anlama çabalarıyla ortaya atılan pek çok kuram ve teoriden biri olan özyeterlilik teorisi (Maddux, 1995, s.3), A. Bandura (1977a; 1977b)'nın sosyal-bilişsel öğrenme teorisine dayanmaktadır (Akçay, 2011:4; Hefferon ve Boniwell, 2014, s.105; Erdoğan ve İraz, 2019, s. 44; Bahar, 2019, s.152). Sosyal bilişsel teori, insanların kendi kendini yansıtma ve kendini düzenleme yeteneğine sahip olduklarını ve çevrelerine karşı sadece pasif reaktörlerden ziyade aktif şekillendirici olduklarını varsayan insan bilişini, eylemini, motivasyonunu ve duygularını anlamlandıran bir yaklaşımdır (Maddux, 1995, s.4).

Günlük yaşamda öz-saygı, öz-güven ve öz-yeterlik kavramları birbirlerinin yerine kullanılsa da (Hefferon ve Boniwell, 2014, ss.104) öz-yeterlik inancı, kendine güven veya öz saygıdan daha spesifik odaklıdır (Carleton vd., 2018, s.187) ve Bandura (1997, s.193) tarafından "bir kişinin gereken davranışı yapması halinde istediği sonuca ulaşacağına dair inancını" olarak tanımlanmıştır. Bazı kuramcılar ise özyeterliliği güven duygusu ile ilişkilendirmiş ve kişinin bazı görevlerini yerine getirirken var olan güven duygusu olarak tanımlamışlardır (Bahar, 2019, s.152). Bir başka tanımda öz-yeterlik; "davranış ve eylem programlarına başlama ve devam etmenin, davranışlardaki kalıcılığın kişinin kendini gösterebilme gücü, davranışsal becerilerine ilişkin beklentileri ve yetenekleri ve çevresel değişim ve taleplerle başarılı bir şekilde başa çıkma olasılığg ile belirlenmesidir" (Maddux, 1995, s.3) şeklinde ifade edilmiştir.

Güven ve etkililik kavramlarıyla da özdeşleştirilen öz-yeterlik (Urgan ve Sevim, 2019) algisı dört kaynaktan beslenmektedir (Bandura, 1997, s.195). Bu dört kaynak kişilerin kendi deneyim ve çalışmalarına dayanan ustalık tecrübeleri, başka insanların tecrübeleri model alma yoluyla paylaşma anlamına gelen dolaylı tecrübeler, bir durumla başa çıkabilmek için alınan önerileri ifade eden sözel ikna ve kişinin korku, kaygı ve stres düzeylerini kontrol edebilmesi olarak belirtilen duygusal durum (Aşkar ve Umay, 2001, s.2; Erdoğan ve İraz, 2019, s.48-49) olarak belirtilmiştir ve Bandura'ya göre öz-yeterlik algısı bireyin, etkinliklerinin seçiminde, güçlükler karşısındaki dayanıklılığın da, çabalarının düzeyinde ve performansında etkilidir (Aşkar ve Umay, 2001, s.1). 
Teknolojinin zorlayıcı aşırı kullanımının nedenlerinden biri olarak karşımıza çıkan (Wiesner, 2017, s.5) ve 2013 yılında Oxford sözlüğüne giren (Ulaştıran, 2017); "fear of missing out" kelimelerinin kısaltılması olan FoMO "heyecan verici ya da ilginç bir olayın şu anda başka bir yerde gerçekleşebileceği endişesi" (oxforddictionaries) olarak tanımlanmış ve özellikle sosyal medya alışkanlığı tarafından uyarıldığı belirtilmiştir (oxforddictionaries). Bu bağlamda FoMO genellikle sosyal medya temelinde "sosyal medyada görülen şeylerden kaynaklanan diğer insanların gideceği heyecan verici olayları kaçırabilme endişesi" (cambridge dictionary) olarak tanımlanmaktadır.

Sözlük anlamları genellikle sosyal medya temelinde yapılsa da aslında FoMO sosyal medya kullanıcılarına özel bir fenomen değildir (Oberst vd., 2017, s.53). Sosyal medyadan bağımsız FoMO tanımlaması Przybylski vd. (2013, s.1841) tarafından "başkalarının kendisi yokken güzel bir deneyimi yaşabileceğine dair endişe" şeklinde yapılmıştır. Bu endişe kişilerin herhangi bir şey kaçırmamak için sürekli başkalarının yaptıklarıyla bağlantılı kalma arzusuna yol açmakta (Przybylski vd., 2013, s.1841), bu arzuda insanların sosyal çevreleriyle sosyal medya üzerinden iletişim kurmalarıyla sonuçlanmaktadır (Oberst vd., 2017, s.53; Wiesner, 2017, s.5).

"Aile ve sosyal çevresiyle ilişki kurabilmek için sosyal medyayı kullanan insanların bağlantı kesilmesi korkusu yaşaması" olarak da adlandırılan (Wiesner, 2017, s.9) FoMO insanların sosyal bir gruba girme ihtiyacından doğmuş, akıllı telefonlar aracılığıyla girdiğimiz sosyal medya bu ihtiyacı karşılamada çok etkin bir kaynak olmuştur (Wiesner, 2017, s.9).

Başlangıçta insanların sosyalleşmesi için yararlı bir kaynak olan sosyal medya, zamanla insanlarda olumsuz bir takım semptomlarm ortaya çıkmasına neden olmuştur. İnsanlarda sürekli bir şeylerin eksik olduğunu hissine yol açan FoMO (Wiesner, 2017, s.5) ile uyku bozukluğu (Rogers ve Barber, 2019), telebaskı (Barber ve Santuzzi, 2017; Rogers ve Barber, 2019) yaşam memnuniyeti (Błachnio ve Przepiórka, 2018) ve stres (Beyens vd., 2016) gibi kişileri olumsuz yönden etkileyen bazı durumlar ile ilişkili bulunmuştur.

Başı aşağıda bir jenerasyon oluşmasına sebep olan FoMO (Wiesner, 2017, s.9) ortaya çıkardığı zararlı etkiler nedeniyle mücadele edilmesi gereken bir durum olarak karşımıza çıkmakta ve özellikle başa çıkmada tüm 
insanlar FoMO'dan eşit düzeyde etkilenmediğinden dolayı daha çok kişisel bir mücadeleyi gerektirmektedir. Alman istatistik portalı Statista'ya göre ABD'de 2013 yılında FoMO'dan etkilenen bireylerin oranı \%56 iken (Maddux, 1995, s.3), Y kuşağının (1980 ile 2000 yılları arasında doğmuş kuşak) \%70'inin tamamen ya da bir şekilde FoMO ile ilgili oldukların belirtilmektedir (Hefferon ve Boniwell, 2014, s.10). Herman tarafından yapılan araştırma sonuçlarına göre ise gelişmiş ülkelerdeki tüm yetişkinlerin yaklaşık \%70'inin FoMO'yu çeşitli derecelerde yaşadığı, \%30'unun FoMO ile iyi başa çıkabildiği, \%25'lik grubun ise FoMO yüzünden mutsuz olduğu bulgulanmıştır (Herman, 2011).

Kişisel bir özellik olmasının yanı sıra insanların faaliyet seçeneklerini ve davranışlarını, engeller karşısında ne kadar mücadele edeceğini ve ne kadar çaba harcayacağını etkileyen öz-yeterlilik ne kadar güçlüyse, başa çıkma çabaları da o kadar güçlü olmaktadır (Bandura, 1977, s.194). Ayrıca özyeterlilik kişinin olası durumlarla başa çıkabilme ile ilgili gereken davranışları ne kadar iyi yürütebileceğine dair kararları ile ilgilidir (Stajkoviç ve Luthans, 1998, s.240). Öz yeterlik teorisi, tüm psikolojik ve davranışsal değişim süreçlerinin bireyin öz-yeterlik algısının değiştirilmesi yoluyla gerçekleştirildiğini iddia etmektedir (Maddux, 1995, s.7).

FoMO'yu ait olma ve deneyimleri kaçırma korkusu ile özdeşleştiren çalışmasında Reagle (2015) FoMO'nun altında yatan duyguları irdelediği çalışmasında; ait olma duygusunun özerklik, öz-yeterlilik ve ilişkililik şeklinde üç kaynaktan kaynakladığını belirtmiştir. Roy Baumeister ve Mark Leary ait olma ihtiyacı konusundaki ampirik çalışmalarında bu ihtiyacın güçlü ve son derece yaygın bir motivasyon olduğu sonucuna varmışlar ve sosyal medya bu ihtiyacı değerlendirmede son derece başarılı olmuştur (Reagle, 2015).

Bu bağlamda kişilerin güçlüklerle mücadele ve başa çıkma düzeylerini etkileyen ve psikolojik ve davranışsal değişim süreçlerini değiştiren özyeterlilik algısının özelliklede yeni nesil için bir hastalık durumuna gelen FoMO ile mücadele etkili bir değişken olacağı düşünülmektedir. Özyeterlilik algısı yüksek olan insanların FoMO düzeylerinin düşük olacağı düşünülmektedir.

Literatürde özyeterlilik öğrenme, tükenmişlik ve problem çözme becerisi (Gürcan, 2005; Haşlaman, 2007; Kotaman, 2008; Köseoğlu, 2010; Bolat, 
2011; Aylar ve Aksin, 2011), FoMO ise siberaylaklık davranışları, problemli internet kullanımı, dijital bağımlılık (Tozkoparan ve Kuzu, 2019; Eşitti, 2015; Özyirmidokuz ve Karakaş, 2019) gibi çok çeşitli değişkenlerle ilişkisi yoğun şekilde araştıılan iki kavram olarak karşımıza çıkmaktadır. Ancak literatürde özyeterlilik ve FoMO arasındaki ilişkinin doğrudan araştırıldığı bir çalışmaya rastlanmamıştır. Bu kapsamda iki kavram arasındaki ilişkinin incelenmesi literatüre katkı sağlayacaktır.

Araştırmanın amacı sağlık bilimleri fakültesine kayıtlı olan öğrencilerin ölçülen genel özyeterlilik düzeylerinin FoMO üzerinde anlamlı bir etkisinin olup olmadığının ve etki düzeyinin belirlenmesidir.

\section{Amaç ve Kapsam}

$\mathrm{Bu}$ araştırma da üniversite öğrencilerinin genel özyeterlilik düzeylerinin FoMO üzerinde anlamlı bir etkisinin olup olmadığının ve varsa etki düzeyinin belirlenerek, literatüre bu alanda katkı sağlaması amaçlanmaktadir.

Araştırmanın uygulama açısından kapsamını Karamanoğlu Mehmetbey Üniversitesi, Sağlık Bilimleri Fakültesi'nde okuyan 450 öğrenci oluşturmaktadır. Toplamda 346 kullanılabilir anketin elde edildiği çalışmada veriler, 02.05.2019-31.05.2019 tarihleri arasında toplanmıştır. Çalışmaya katılmayı kabul eden öğrencilerin, en az bir sosyal medya hesabına ve akıllı telefona sahip olmaları ön koşulu aranmıştır.

Çalışmanın yapılabilmesi için Karamanoğlu Mehmetbey Üniversitesi Sağlık Bilimleri Enstitüsü Etik Kurul Başkanlığı'ndan 24.04.2019 tarih ve 04-2019/22 sayılı yazılı izin alınmıştır.

\section{Yöntem}

Araştırmada veri toplama yöntemi olarak nicel veri toplama yöntemlerinden anket yöntemi (Yazıcıŏ̆lu ve Erdoğan, 2014, s.9) ve değişkenler arasındaki ilişkinin araştırıldığı bağıntısal araştırma modeli kullanılmıştır (Gurbetoğlu, 2018). 


\section{Araştırmanın Varsayımları ve Sinırlılıkları}

Bu araştırma Karamanoğlu Mehmetbey Üniversitesi Sağlık Bilimleri Fakültesi'nde okuyan öğrencileri kapsadığı için araştırma bulgularının ve sonuçlarının tüm eğitim örgütleri için genellenmesinde bu hususun dikkate alınması önerilmektedir.

Bu çalışma kapsamında sorulan sorular ve kurulan model, belli ölçüm araçları, belirlenen örneklem, kullanılan yöntem kapsamında incelenerek sinırlandırılmıştır. Araştırma sonucunda elde edilen niceliksel verilerin geçerliliği ve güvenilirliği çalışmada kullanılan anket tekniğinin özellikleriyle sinırlıdır.

$\mathrm{Bu}$ araştırma kapsamına sadece özyeterliliğin FoMO ile ilişkisi ve etkisini ele almaktadır. FoMO'yu etkileyebilecek muhtemel diğer faktörler dikkate alınmamıştır. Ayrıca örneklemde yer alan öğrencilerin anket sorularını doğru ve samimi cevapladıkları, ölçeklerin ve istatistiksel yöntemlerin hipotezleri test etmede yeterli oldukları varsayılmıştır.

\section{Ölçekler}

Araştırmada kullanılan Genel Özyeterlilik ölçeği Sherer vd. (1982) tarafından geliştirilmiş, Türkçe uyarlaması ise Yıldırım ve İlhan (2010) tarafından yapılmıştır. Türkçe formu 17 maddeden oluşan ölçeğin güvenilirliği Sherer vd. (1982) tarafından 0,86, Yıldırım ve İlhan (2010) tarafından 0,80, Tırpan (2016) tarafından 0,80 olarak bulgulanmıştır. Ölçekte sorular 5'li likert tarzında hazırlanmıştır. Ölçekte 11 soru (2., 4., 5., 6., 7., 10., 11., 12., 14., 16. ve 17. sorular) ters, 6 soru (1., 3., 8., 9., 13. ve 15. sorular) düz soru niteliğindedir. Her soru puanı 1-5 arasında değişmekte, puanlar yükseldikçe özyeterlilik inancı artmaktadır şeklinde yorumlanmıştır.

Araştırmada kullanılan FoMO ölçeği ise Przybylski tarafından geliştirilen, 10 sorudan oluşan beşli Likert tipi bir ölçektir. Türkçe güvenirlilik çalışması Gökler vd. (2016) tarafından 200 üniversite öğrencisi örneklemi kullanılarak yapılmıştır. Ölçekte yer alan her madde 1- 5 puan arasında puanlandırılmaktadır. Ölçekten alınan puan arttıkça bireyin gelişmeleri kaçırma korkusunun olma olasılığı artmaktadır şeklinde değerlendirilecektir. Gökler vd. (2016) ölçeğin Cronbach alfa katsayısını 0.81 olarak saptamıştır. 


\section{Yapısal Geçerlilik ve Güvenilirlik Analizleri}

Araştırma grubundan elde edilen verilerin açımlayıcı faktör analizine uygun olup olmadığı belirlemek için Kaiser-Meyer-Olkin (KMO) ve Barlett testine bakılmıştır. KMO değerinin 0,50'den düşük olması durumunda verilerin faktör analizine uygun olmadığı sonucu çıkmaktadır (Kalaycı, 2010, ss.322). KMO değerlerinin nasıl yorumlanacağı Tablo 1'de verilmiştir.

Tablo 1. KMO değerleri ve yorumları

\begin{tabular}{ll}
\hline KMO değeri & Yorum \\
\hline 0,90 & Mükemmel \\
\hline 0,80 & Çok iyi \\
\hline 0,70 & Iyi \\
\hline 0,60 & Orta \\
\hline 0,50 & Zaylf \\
\hline $0,50^{\prime}$ 'nin altı & Kabul edilemez \\
\hline
\end{tabular}

Kaynak: (Kalaycl, 2010:322)

Özyeterlilik Ölçeği için yapılan Barlett testi anlamlı $(p=0,00)$ ve KMO değeri 0,88 çıktığ 1 için verilerimiz faktör analiz yapmaya mükemmele yakın uygundur şeklinde yorumlanmıştır. Özyeterlilik ölçeği için yapılan açımlayıcı faktör analizinde orijinal ölçek ile uyumlu şekilde 3 faktör tespit edilmiştir. Faktör analizinde ölçeğin 15. sorusu düşük ortak varyansa ve düşük faktör yüküne sahip oldukları için ölçekten çıkarılmıştır. Faktörlere dahil olan sorular incelenerek ölçekle uyumlu şekilde isimlendirilmişlerdir. Faktörler orijinal ölçekle uyumlu şekilde, başlama $(2,5,6,7)$, y1lmama $(4,10,11,12,14,16,17)$ ve sürdürme $(1,3,8,9,13)$ şeklinde isimlendirilmiştir. Faktörler varyansın \% 42,14'ünü açılayabilmektedirler. Faktör analizinden sonra yapılan güvenilirlik analizi sonucu ölçeğin Cronbach $\alpha=0,84$, yılmama boyutunun Cronbach $\alpha=0,84$, başlama boyutunun Cronbach $\alpha=0,74$ ve israr boyutunun Cronbach $\alpha=0,66$ bulunmuştur. $\mathrm{Bu}$ sonuçlar ölçeğimizin güvenilir bir ölçek olduğunu göstermektedir.

Açımlayıcı faktör analizinden sonra Özyeterlilik Ölçeğinin AMOS 22 yazılımı ile doğrulayıcı faktör analizi yapılarak faktör yapısı doğrulanmıştır. 


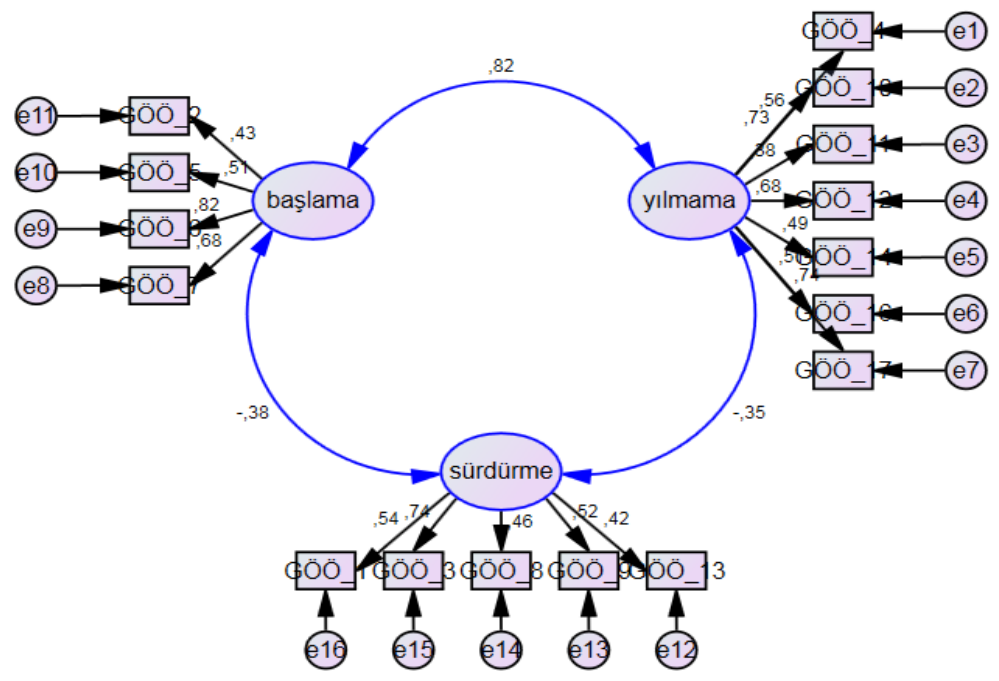

Şekil 1. Özyeterlilik ölçeğinin doğrulayıcı faktör analizi sonuçları

Analizde hesaplanan indeks değerleri;

Tablo 1. Özyeterlilik ölçeği indeks değerleri

\begin{tabular}{|c|c|c|c|c|}
\hline Index & $\begin{array}{l}\text { Mükemmel } \\
\text { Uyum }\end{array}$ & $\begin{array}{l}\text { Kabul Edilebilir } \\
\text { Uyum }\end{array}$ & $\begin{array}{l}\text { Araştırma } \\
\text { Bulgusu }\end{array}$ & Sonuç \\
\hline $\mathrm{x}^{2} / \mathrm{sd}$ & $0-3$ & $3-5$ & 1,70 & $\begin{array}{l}\text { Mükemmel } \\
\text { Uyum }\end{array}$ \\
\hline RMSEA & $00 \leq$ RMSEA $\leq .05$ & $\begin{array}{l}.05 \leq \text { RMSEA } \leq \\
.10\end{array}$ & 0,04 & $\begin{array}{l}\text { Mükemmel } \\
\text { Uyum }\end{array}$ \\
\hline CFI & $95 \leq \mathrm{CFI} \leq 1.00$ & $.90 \leq \mathrm{CFI} \leq .95$ & 0,94 & İyi uyum \\
\hline NFI & $95 \leq \mathrm{NFI} \leq 1.00$ & $.90 \leq \mathrm{NFI} \leq .95$ & 0,90 & İyi uyum \\
\hline
\end{tabular}

Kaynak: (Schumacker ve Lomax, 1996; Çapık, 2014)

Özyeterlilik ölçeğinin doğrulayıcı faktör analizi indeks değerlerine göre Ki-kare (X2 ) uyum istatistiği 1,70 olarak bulunmuştur. Model mükemmel uyum göstermektedir. RMSEA değeri 0,04 olarak bulunmuştur ve mükemmel uyum göstermektedir. CFI değeri 0.94 olarak bulunmuştur ve bulunan CFI değeri iyi uyumu gösterir. NFI değeri 0,90 
olarak bulgulanmıştır. Sonuçlara genel olarak değerlendirildiğinde modelin doğrulandığı söylenebilir.

Gelişmeleri Kaçırma Korkusu ölçeği için açımlayıcı faktör analizi yapmadan önce $\mathrm{KMO}$ ve Barlett testine bakılmıştır. Barlett testi anlamlı $(p=0,00)$ ve KMO değeri 0,789 çıtığ maya uygundur şeklinde yorumlanmıştır. Gelişmeleri Kaçırma Korkusu ölçeği için yapılan açımlayıcı faktör analizinde orijinal ölçeğin tek faktörlü yapısına rağmen 2 faktörlü bir yapı tespit edilmiştir. Faktör analizinde ölçeğin 4. madde düşük ortak varyansa ve düşük faktör yüküne sahip olduğu için ölçekten çıkarılmıştır. Faktörlere dahil olan sorular incelenerek uyumlu şekilde isimlendirilmişlerdir. 1. faktör merak (1,2,3), 2. faktör önem $(5,6,7,8,9,10)$ şeklinde isimlendirilmiştir. Faktörler varyansın \% 51,16 ' sinı açıklayabilmektedirler. Faktör analizinden sonra yapılan güvenilirlik analizi sonucu ölçeğin Cronbach $\alpha=0,80$, merak boyutunun Cronbach $\alpha=0,85$ ve önem boyutunun Cronbach $\alpha=0,79$ bulunmuştur. $\mathrm{Bu}$ sonuçlar ölçeğimizin güvenilir bir ölçek olduğunu göstermektedir.

Açımlayıcı faktör analizinden sonra FoMO ölçeğine AMOS 22 yazılımı ile doğrulayıcı faktör analizi yapılarak faktör yapısı doğrulanmıştır.

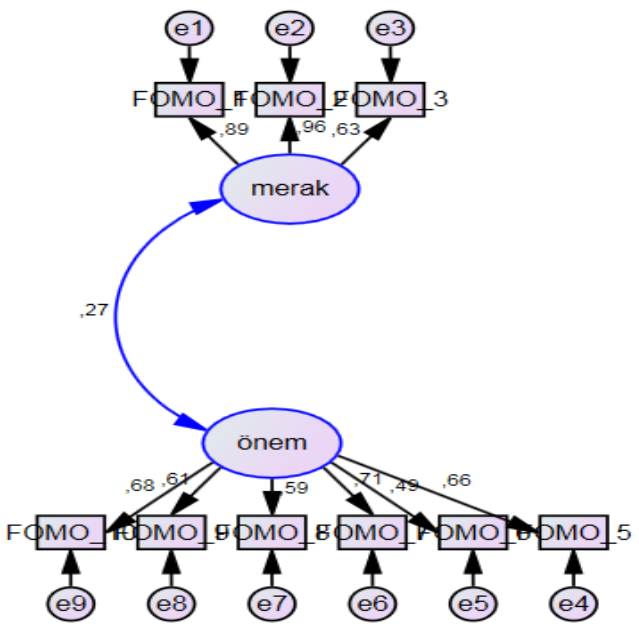

Şekil 2. FoMO ölçeği doğrulayıcı faktör analizi sonuçları Analizde hesaplanan indeks değerleri; 
Tablo 2. FoMO ölçeği indeks değerleri

\begin{tabular}{lllll}
\hline Index & $\begin{array}{l}\text { Mükemmel } \\
\text { Uyum }\end{array}$ & $\begin{array}{l}\text { Kabul } \\
\text { Edilebilir Uyum }\end{array}$ & $\begin{array}{l}\text { Araştırma } \\
\text { Bulgusu }\end{array}$ & Sonuç \\
\hline $\mathrm{x}^{2} /$ sd & $0-3$ & $3-5$ & 3,47 & İyi Uyum \\
\hline RMSEA & $00 \leq$ RMSEA $\leq .05$ & $.05 \leq$ RMSEA $\leq .10$ & 0,08 & İyi Uyum \\
\hline CFI & $95 \leq \mathrm{CFI} \leq 1.00$. & $.90 \leq \mathrm{CFI} \leq .95$ & 0,94 & İyi Uyum \\
\hline NFI & $95 \leq \mathrm{NFI} \leq 1.00$ & $.90 \leq \mathrm{NFI} \leq .95$ & 0,92 & İyi Uyum \\
\hline
\end{tabular}

(Schumacker ve Lomax, 1996; Çapık, 2014:199; Meydan ve Şeşen, 2015)

FoMO ölçeğinin doğrulayıcı faktör analizi indeks değerlerine göre Kikare (X2 ) uyum istatistiği 3,47 olarak bulunmuştur. Model iyi uyum göstermektedir. RMSEA değeri 0,08 olarak bulunmuştur ve iyi uyum göstermektedir. CFI değeri 0.94 olarak bulunmuştur ve bulunan CFI değeri iyi uyumu gösterir. NFI değeri 0,92 olarak elde edilmiştir ve modelin iyi uyum sağladığını gösterir. Sonuçlar genel olarak değerlendirildiğinde modelin doğrulandığı söylenebilir.

\section{Test Edilecek Hipotezler}

Çalışmada test edilecek hipotezler aşağıda verilmiştir.

Tablo 3. Test edilecek hipotezler

\begin{tabular}{ll}
\hline H1 & Özyeterliliğin başlama boyutu FoMO'nun merak boyutunu etkiler \\
\hline H2 & Özyeterliliğin başlama boyutu FoMO'nun önem boyutunu etkiler \\
\hline H3 & Özyeterliliğin yılmama boyutu FoMO'nun merak boyutunu etkiler \\
\hline H4 & Özyeterliliğin yılmama boyutu FoMO'nun önem boyutunu etkiler \\
\hline H5 & Özyeterliliğin sürdürme boyutu FoMO'nun merak boyutunu etkiler \\
\hline H6 & Özyeterliliğin sürdürme boyutu FoMO'nun önem boyutunu etkiler \\
\hline H7 & Özyeterliliğin başlama boyutu FoMO'yu etkiler. \\
\hline H8 & Özyeterliliğin yılmama boyutu FoMO'yu etkiler. \\
\hline H9 & Özyeterliliğin sürdürme boyutu FoMO'yu etkiler. \\
\hline
\end{tabular}

\section{Bulgular}

\section{Demografik Bulgular}

Araştırma kapsamındaki öğrencilerin demografik özelliklerine ait bilgiler Tablo 5'te verilmiştir. 
Tablo 4. Katılımcıların demografik özellikleri

\begin{tabular}{llll}
\hline Özellikler & & $\mathrm{f}$ & $\%$ \\
\hline \multirow{2}{*}{ Cinsiyet } & Kadın & 279 & 80,6 \\
& Erkek & 67 & 19,4 \\
\hline \multirow{4}{*}{ Yaş } & 18 yaş & 35 & 10,1 \\
& 19 yaş & 72 & 20,8 \\
& 20 yaş & 82 & 23,7 \\
& 21 yaş & 73 & 21,1 \\
& 22 yaş & 46 & 13,3 \\
Okuduğu Sınıf & 23 yaş & 24 & 6,9 \\
& 24 yaş ve üzeri & 14 & 4,1 \\
\hline \multirow{3}{*}{ Okuduğu Bölüm } & 1.sinıf & 157 & 45,4 \\
& 2. sinıf & 75 & 21,7 \\
& 3.sinıf & 60 & 17,3 \\
& 4. sinıf & 54 & 15,6 \\
\hline \multirow{3}{*}{ Yaşanılan Yer } & Hemşirelik & 258 & 74,6 \\
& Sağlik Yönetimi & 41 & 11,8 \\
& Besl. ve Diete. & 47 & 13,6 \\
\hline & Aile Yanı & 50 & 14,5 \\
& Yurt & 270 & 78,0 \\
& Arkadaşlarla Evde & 15 & 4,3 \\
& Akraba Yanı & 4 & 1,2 \\
& Evde Tek & 7 & 2,0 \\
\hline
\end{tabular}

Tablo 5'e göre katılımcıların çoğunluğu $(\% 80,6)$ kadındır. Katılımcıların yaş dağılımları değerlendirildiğinde en büyük çoğunluk 20 yaş $(\% 23,7)$ grubuna ait olsa da, 21 yaş $(\% 21,1)$ ve 19 yaş $(20,8)$ grubunun katılımcı sayıları birbirine oldukça yakındır. Katılımcıların \%45,4'ü 1 . sınıf öğrencisi ve \%74,6'sı hemşirelik bölümü öğrencisi olarak karşımıza çıkmaktadır. Son olarak öğrencilerini \%78'i yurtta kalarak eğitim hayatına devam etmektedir.

\section{Korelasyon ve Regresyon Analizi Sonuçlarn}

Bağımsız değişkenimiz olan özyeterliliğin FoMO ile arasında doğrusal bir ilişki olup olmadığı, varsa bu ilişkinin derecesini belirlemek için Pearson Korelasyon analizi yapılmıştır. Korelasyon analizinde amaç; bağımsız değişken değiştiğinde bağımlı değişkenin ne yönde değişeceğini görmektir (Sungur, 2010, s.115). Değişkenlerin sürekli olması ve normal dağılmaları korelasyon analizi yapabilmek için gereklidir (Sungur, 2010, s.115). 
Korelasyon katsayısı " $\mathrm{r}$ " ile gösterilir ve 1 ile +1 arasında değer alır. Pearson korelasyon katsayısı; 0,00-0,25 arası çok zayıf, 0,26-0,49 zayıf ilişki, 0,50-0,69 orta düzey ilişki, 0,70-0,89 yüksek düzey ilişki ve 0,90-1,00 çok yüksek ilişki şeklinde yorumlanacaktır (Sungur, 2010, s.115-116).

Tablo 5. Özyeterlilik ve alt boyutlarn ile FoMO ve alt boyutlarn arasındaki korelasyon analizi sonuçları

\begin{tabular}{llll}
\hline & $\begin{array}{l}\text { Merak } \\
\text { Boyutu }\end{array}$ & $\begin{array}{l}\text { Önem } \\
\text { Boyutu }\end{array}$ & FoMO \\
\hline Başlama Boyutu &,$- 296^{* *}$ &,- 102 &, $204^{* *}$ \\
\hline Yılmama Boyutu &,$- 263^{* *}$ &,- 072 &,$- 167^{* *}$ \\
\hline Sürdürme Boyutu &,- 104 &,- 027 &,- 065 \\
\hline Özyeterlilik &,$- 294^{* *}$ &,- 087 &,$- 192^{* *}$ \\
\hline
\end{tabular}

** Correlation is significant at the 0,01 level (2-tailed)

Araştırma bulgularına göre sağlık bilimleri fakültesi öğrencilerinin özyeterlilik düzeyleri ile FoMO düzeyleri arasında negatif anlamlı ve çok zayıf düzey bir ilişki bulgulanmıştır $(r=-0,192 ; p<0,01)$. Özyeterlilik ölçeğinin alt boyutları ile gelişmeleri kaçırma korkusu düzeyleri değerlendirildiğinde; başlama boyutu ile FoMO arasında negatif anlamlı ve çok zayıf düzey bir ilişki $(r=-0,204 ; p<0,01)$, yılmama boyutu ile FoMO arasında negatif anlamlı ve çok zayıf düzey bir ilişki $(r=-0,167 ; \mathrm{p}<0,01)$ bulgulanmıştır Özyeterlilik ölçeğinin alt boyutları ile FoMO alt boyutları düzeyleri incelendiğinde başlama boyutu ile merak boyutu arasında negatif anlamlı ve zayıf ilişki bulgulanmıştır $(r=-0,296 ; \mathrm{p}<0,01)$. Yılmama ile merak arasında negatif anlamlı ve zayıf ilişki bulgulanmıştır $(r=-0,263$; $\mathrm{p}<0,01)$.

Korelasyon analizinin ardından bağımlı değişken ile birden fazla bağımsız (çoklu regresyon) değişken arasındaki ilişkilerin bir matematiksel eşitlik ile açıklanması için (Küçüksille, 2010, s.199) çoklu regresyon analizi yapılmıştır. Çoklu regresyon analizinin yapılabilmesi için gerekli varsayımlar olan bağımlı değişkenin sürekli veya kesikli niceliksel (sayısal) veri türünde olması, bağımsız değişkenlerin sürekli-kesikli niceliksel (sayısal) veri veya niteliksel veri türünde olması, gözlem sayısının (n), bağımsız değişken sayısının en az 5 katı kadar olması ve bağımsız değişkenler arasında yüksek korelasyon olmaması (Dönmez, 2014, s.205) şartları sağlanmıştır. Sosyal bilimlerde kullanılan likert tarzı ölçekler 
metrik kabul edilir (Öztürk, 2017, s.61; Dönmez, 2014, s.205; Tezbaşaran, 2008, s.31; Erdoğan ve İraz, 2019). Özyeterlilik ölçeğinin alt boyutları olan başlama ve yılmama boyutları için olması gereken gözlem sayısı (n) $15^{\prime}$ dir. Çalışmada ki gözlem sayısı 346'dır.

Bağımsız değişkenler arasında korelasyonun yüksek olması çoklu değişkenlik olduğu anlamına gelir (45). Araştırma bulguları incelendiğinde özyeterliliğin alt boyutları arasında yüksek korelasyona $(r=0,177)$ rastlanmamıştır.

Özyeterliliğin alt boyutları ile FoMO ve alt boyutları arasındaki alt boyutları arasındaki doğrusal ilişkileri test etmek, FoMO ve alt boyutlarındaki değişimin ne kadarının özyeterlilik boyutları tarafından açıklanabildiğini araştırmak ve değişkenler arasındaki ilişkiyi matematiksel olarak ifade etmek amacıyla çoklu doğrusal regresyon analizi yapılmıştır. Özyeterlilik alt boyutları ile FoMO'nun alt boyutu merak arasındaki regresyon analizi sonuçları Tablo 7 'de verilmiştir.

Çoklu bağlantı sorununun saptanmasında kullanılan bir diğer önemli yöntem VIF (varyans artış faktörleri)'dır (Eroğlu, 2010, ss.224). 10'un üzerindeki VIF değerleri ciddi bir çoklu doğrusal bağlantı olduğunu gösterir (Sevinç, 2013, s.2; Dönmez, 2014, s. 207). Regresyon modelinde oto korelasyon olup olmadığ Otokorelasyon (hataların bağımsızlığı) herhangi bir zaman serisinin veya eşleştirilmiş zaman serilerinim değerleri arasındaki korelasyondur (Eroğlu, 2010, s. 224-225). Genelde 1,5 ile 2,5 civarındaki bir D-W değeri oto korelasyon olmadığının göstergesidir (Dönmez, 2014:207).

Tablo 7'deki $F$ değeri 12,236 ve $p$ değeri 0,00 olduğundan oluşturulan regresyon modeli istatistiksel olarak anlamlıdır. VIF (varyans şişme değeri) değerleri 10'dan küçük bulgulanmıştır. Bu bulguya göre çoklu bağlantı sorunu yoktur $(\mathrm{VIF}<10)$. $\mathrm{D}-\mathrm{W}$ (otokorelasyona işaret eder) değeri 1,929 olarak bulgulanmıştır. Bu bulguya göre oto korelasyon yoktur.

Regresyon katsayılarının anlamlılığına işaret eden $t$ istatistiklerine göre; başlama boyutu ( $\mathrm{t}=-3,088 \mathrm{p}=, 02<0,05)$, merak boyutu ile istatistiksel olarak anlamliyken, yılmama boyutu $(\mathrm{t}=-1,702 ; \mathrm{p}=0,090>0,05)$ ve sürdürme boyutu ( $\mathrm{t}=-, 633 ; \mathrm{p}=0,527>0,05)$ merak boyutu ile istatistiksel olarak anlamsızdır.

Değişkenler arasında pozitif ilişki $(R=0,295)$ vardır. Çoklu regresyon analizlerinde basit regresyon analizinde faklı olarak adjusted R2 değerini 
kullanmak daha doğrudur. Çünkü çoklu regresyonda modeller dahil edilen değişken sayısı arttıkça R2 otomatik olarak artar (Erdoğan ve İraz, 2019). Bağımsız değişkenlerin bağımlı değişkeni açıklama oranı olan düzeltilmiş $R^{2}=0,082$ olarak hesaplanmıştır. Yani FoMO'nun merak boyutundaki değişimlerin \%082'inin özyeterlilik alt boyutlarından başlama düzeyi ile açıklandığını göstermektedir.

Tablo 6. Özyeterlilik alt boyutlarn ile merak boyutu arasındaki regresyon analizi sonuçları

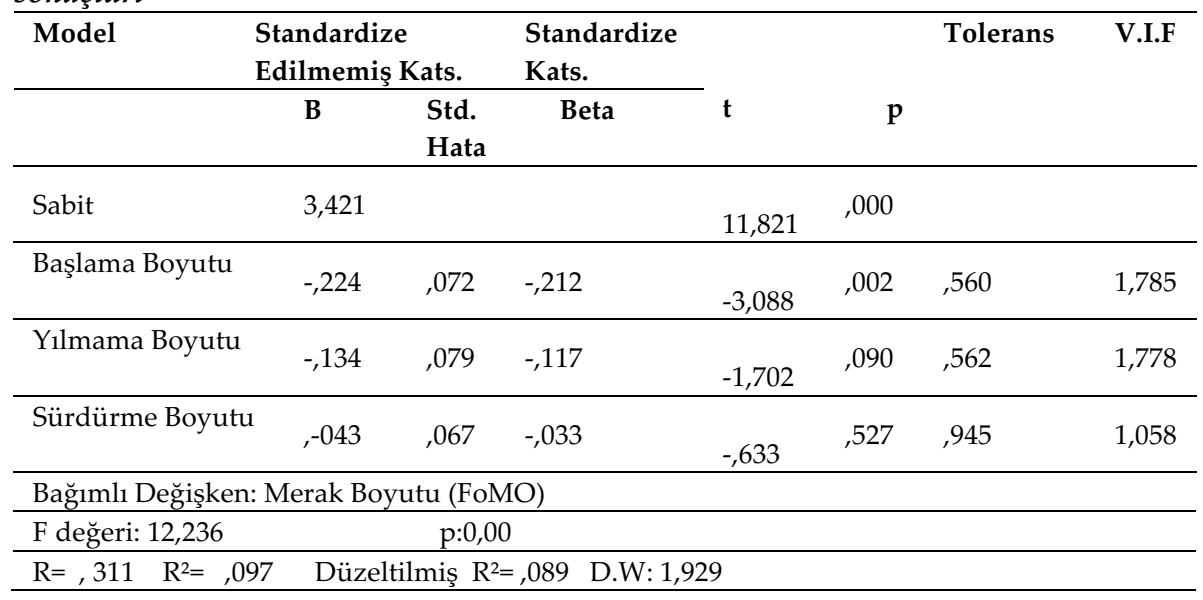

Özyeterlilik alt boyutları ile FoMO'nun alt boyutu olan önem arasındaki regresyon analizi sonuçları Tablo $8^{\prime}$ de verilmiştir.

Tablo 7. Özyeterlilik alt boyutlarn ile önem boyutu arasindaki regresyon analizi sonuçları

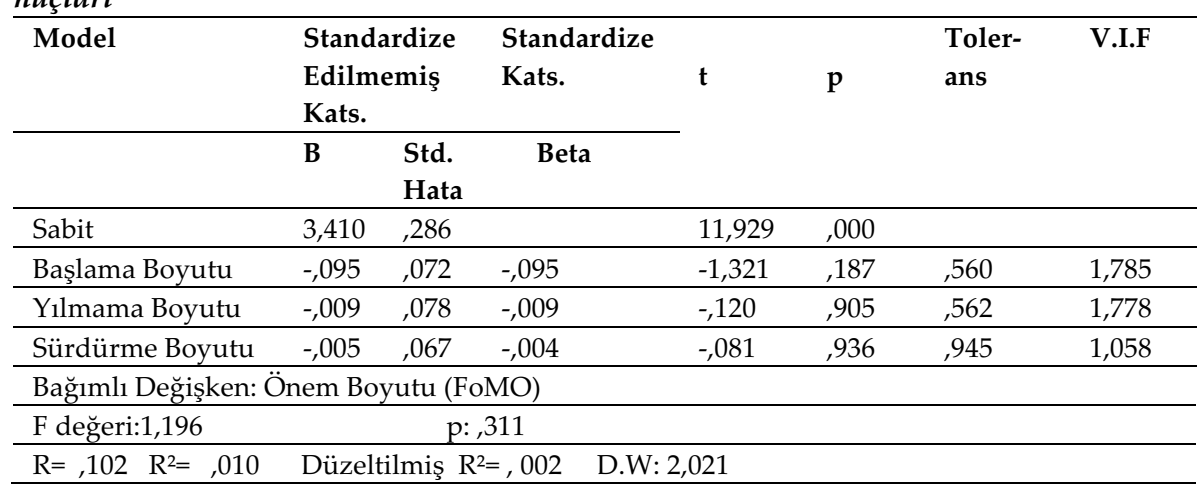


Tablo 8'deki F değeri 1,304 ve p değeri 0,311>0,05 olduğundan oluşturulan regresyon modeli istatistiksel olarak anlamsızdır.

Özyeterlilik alt boyutları ile FoMO arasındaki regresyon analizi sonuçları Tablo 9' da verilmiştir.

Tablo 8. Özyeterlilik alt boyutlarn ile FoMO arasındaki regresyon analizi sonuçları

\begin{tabular}{|c|c|c|c|c|c|c|c|}
\hline \multirow[t]{3}{*}{ Model } & \multirow{2}{*}{\multicolumn{2}{|c|}{$\begin{array}{l}\text { Standardize } \\
\text { Edilmemiş } \\
\text { Kats. }\end{array}$}} & \multicolumn{2}{|l|}{ Standardize } & \multirow{3}{*}{$\begin{array}{l}\text { An- } \\
\text { lam } \\
\text { düzey } \\
\text { i }\end{array}$} & \multirow{3}{*}{$\begin{array}{l}\text { Toler- } \\
\text { ans }\end{array}$} & \multirow[t]{3}{*}{ V.I.F } \\
\hline & & & Kats. & \multirow[t]{2}{*}{$\mathbf{t}$} & & & \\
\hline & B & $\begin{array}{l}\text { Std. } \\
\text { Hata }\end{array}$ & Beta & & & & \\
\hline Sabit & 3,414 & ,237 & & 14,377 & ,000 & & \\
\hline Başlama Boyutu &,- 138 & ,059 &,- 164 & $-2,315$ & ,021 & ,560 & 1,785 \\
\hline Yilmama Boyutu &,- 051 & 064 &,- 056 &,- 787 & ,432 &, 562 & 1,778 \\
\hline Sürdürme Boyutu &,- 018 & ,055 &,- 018 &,- 322 & ,748 & ,945 & 1,058 \\
\hline \multicolumn{8}{|c|}{ Bağımlı Değişken: FoMO } \\
\hline F değeri:5,215 & \multicolumn{4}{|c|}{ p: 0,002} & & & \\
\hline $\mathrm{R}=, 209$ & $=044$ & & Düzeltilmiş $R$ & 0,35 & \multicolumn{2}{|c|}{ D.W: 2,010} & \\
\hline
\end{tabular}

Tablo 8'deki F değeri 5,215 ve p değeri 0,02 olduğundan oluşturulan regresyon modeli istatistiksel olarak anlamlıdır. VIF (varyans şişme değeri) değerleri 10'dan küçük bulgulanmıştır. Bu bulguya göre çoklu bağlantı sorunu yoktur (VIF<10). D-W (otokorelasyona işaret eder) değeri 2,010 olarak bulgulanmıştır. Bu bulguya göre oto korelasyon yoktur.

Regresyon katsayılarının anlamlılığına işaret eden $t$ istatistiklerine göre; başlama boyutu ( $\mathrm{t}=-2,315 \mathrm{p}=, 02<0,05)$, FoMO ile istatistiksel olarak anlamliyken, yılmama ( $\mathrm{t}=-, 787 ; \mathrm{p}=0,432>0,05$ ) ve sürdürme boyutları ( $\mathrm{t}=-$ ,322; $\mathrm{p}=0,748>0,05$ ) FoMO ile istatistiksel olarak anlamsızdır.

Değişkenler arasında negatif ilişki $(R=0,209)$ vardır. Bağımsız değişkenlerin bağımlı değişkeni açıklama oranı olan düzeltilmiş $\mathrm{R}^{2}=0,035$ olarak hesaplanmıştır. Yani FoMO değişimlerin \%035' inin özyeterlilik alt boyutlarından başlama düzeyi ile açıklandığını göstermektedir. Başlama düzeyindeki 1 birimlik artış FoMO düzeyini 0,138 birim azaltmaktadır.

Yapılan regresyon analizi sonucunda kabul ve red edilen hipotezler tablo $10^{\prime}$ da sunulmuştur. 
Tablo 9. Hipotezlerin kabul-red durumları

\begin{tabular}{lll}
\hline & Hipotezler & Kabul/Red \\
\hline H1 & Özyeterliliğin başlama boyutu FoMO'nun merak boyutunu etkiler. & Kabul \\
\hline H2 & Özyeterliliğin başlama boyutu FoMO'nun önem boyutunu etkiler. & Red \\
\hline H3 & Özyeterliliğin yılmama boyutu FoMO'nun merak boyutunu etkiler. & Red \\
\hline H4 & Özyeterliliğin yılmama boyutu FoMO'nun önem boyutunu etkiler. & Red \\
\hline H5 & Özyeterliliğin sürdürme boyutu FoMO'nun merak boyutunu etkiler. & Red \\
\hline H6 & Özyeterliliğin sürdürme boyutu FoMO'nun önem boyutunu etkiler. & Red \\
\hline H7 & Özyeterliliğin başlama boyutu FoMO'yu etkiler. & Kabul \\
\hline H8 & Özyeterliliğin yılmama boyutu FoMO'yu etkiler. & Red \\
\hline H9 & Özyeterliliğin sürdürme boyutu FoMO'yu etkiler. & Red \\
\hline
\end{tabular}

\section{Tartışma ve Sonuçlar}

Karamanoğlu Mehmetbey Üniversitesi Sağlık Bilimleri Fakültesi'nde okuyan 450 öğrencilerin Özyeterlilik düzeylerinin FoMO düzeylerini nasıl etkilediğini araştırdığımız bu çalışmada özyeterliliğin FoMO'yu düşük oranda etkilediği ortaya konulmuştur. Sonuçlar kısaca şu şekildedir;

1. Özyeterlilik ölçeği geçerlik ve güvenilirlik analizleri ile incelenmiştir. Ölçeğin faktör yapısının açımlayıcı faktör analizi ile incelenmesi sonucunda özdeğeri 1'in üzerinde olan 2 faktör belirlenmiştir. Belirlenen 2 faktör varyansın $\% 48,13$ açıklamaktadır. Bu oran özgün formda bildirilen \%26,5 (Sherer ve ark. 1982) ve Yıldırım ve İlhan (2010) tarafından açıklanan \%41,5'in üstündedir. Genel özyeterliliğin belirlenen 2 faktörlü yapısı doğrulayıcı faktör analizi ile doğrulanmıştır. Genel Özyeterlilik ölçeğine yapılan güvenilirlik analizi sonucunda Cronbach $\alpha=0,77$ olarak bulgulanmış ve ölçeğimizin güvenilir bir ölçek olduğu ortaya konulmuştur ve literatür ile uyumlu bir sonuç bulgulanmıştır (Chen ve ark. 2001; Sohng veark. 2002, Lau-Walker 2004 ve Kim ve Omizo 2005; Yıldırım ve İlhan, 2010).

2. FoMO ölçeği geçerlik ve güvenilirlik analizleri ile incelenmiştir. Ölçeğin faktör yapısının açımlayıcı faktör analizi ile incelenmesi sonucunda özdeğeri 1'in üzerinde olan 2 faktör belirlenmiştir. Belirlenen 2 faktör varyansın \%62,89'unu açıklamaktadır. Bu iki faktörlü yap1 Gökler vd. (2016) tarafından yapılan çalışma bulgusuyla uyuşmamaktadır. Gökler vd. (2016) çalışmalarında orijinal ölçek ile paralel bir şekilde tek faktörlü bir yapı ile toplam varyansın \%39,4'ünü açıklayan bir yap1 ortaya koymuştur. FoMO ölçeğinin belirlenen 2 faktörlü 
yapısı doğrulayıcı faktör analizi ile doğrulanmıştır. FoMO ölçeğine yapılan güvenilirlik analizi sonucunda Cronbach $\alpha=0,77$ olarak bulgulanmış ve ölçeğimizin güvenilir bir ölçek olduğu ortaya konulmuştur ve literatür ile uyumlu bir sonuç bulgulanmıştır (Gökler vd. 2016; Aydın, 2018)

3. Çalışmadaki hipotezleri test etmek ve bağımsız değişkenimiz olan özyeterliliğin FoMO ile arasında doğrusal bir ilişki olup olmadığı, varsa bu ilişkinin derecesini belirlemek için Pearson Korelasyon analizi yapılmıştır. Araştırma bulgularına göre sağlık hizmetleri fakültesi öğrencilerinin özyeterlilik düzeyleri ile FoMO düzeyleri arasında negatif anlamlı ve çok zayıf düzey bir ilişki bulgulanmıştır $(r=-0,178$; $\mathrm{p}<0,01)$. Özyeterlilik ölçeğinin alt boyutları ile gelişmeleri kaçırma korkusu düzeyleri değerlendirildiğinde; başlama boyutu ile FoMO arasında negatif anlamlı ve çok zayıf düzey bir ilişki bulgulanmıştır $(r=-0,204 ; \mathrm{p}<0,01)$. Özyeterlilik ölçeğinin alt boyutları ile FoMO alt boyutları düzeyleri incelendiğinde başlama boyutu ile merak boyutu arasında negatif anlamlı ve zayıf ilişki bulgulanmıştır $(r=-0,293$; $\mathrm{p}<0,01)$.

4. Özyeterliliğin alt boyutları ile FoMO ve alt boyutları arasındaki alt boyutları arasındaki doğrusal ilişkileri test etmek, FoMO ve alt boyutlarındaki değişimin ne kadarının özyeterlilik boyutları tarafından açılanabildiğini araştırmak ve değişkenler arasındaki ilişkiyi matematiksel olarak ifade etmek amacıyla çoklu doğrusal regresyon analizi yapılmıştır. Regresyon analizi sonuçları;

- FoMO'nun merak boyutundaki değişimlerin \%082' 'inin özyeterlilik alt boyutlarından başlama düzeyi ile açılandığını,

- FoMO'nun önem boyutu üzerinde özyeterliliğin hiçbir boyutunun anlamlı etkisinin bulunmadığını,

- FoMO değişimlerin \%037' sinin özyeterlilik alt boyutlarından başlama düzeyi ile açıklandığını göstermektedir.

Literatürde Özyeterlilik ve FoMO ilişkisinin araştırıldığı başka bir çalışmaya rastlanılmamıştır. Ancak FoMO'nun motivasyonel, duygusal ve davranışsal korelasyonlarını araştıran Przybylski vd. (2013) çalışmalarında kendini daha az yeterli hisseden bireylerin daha yüsek düzeyde kaybetme korkusu yaşadığını bulgulamıştır. Yine Przybylski yaşam memnuniyeti ile FoMO'yu negatif olarak ilişkilendirmiştir. Yaşam doyumu ile 
özyeterlik arasında ise pozitif ilişki bulgulayan çalışmalara rastlanırken (Akgündüz, 2016), yaşam memnuniyetsizliğinin bir ürünü olan tükenmişlik ile de özyeterlilik arasında negatif ilişki bulgulayan pek çok çalışmaya (Karahan ve Bolat, 2011; Bolat, 2011; Çelikkaleli, 2011) rastlanmaktadır. Özyeterlik ile tükenmişlik arasında negatif ilişki bulgulanırken FoMO ve tükenmişlik arasında birbirini pozitif yönde etkileyen çalışmalar (Barber ve Cucalon, 2017; Elhai vd. 2016) bulunmaktadır. Özyeterliliğin bir başka pozitif etki sağladığı alan bağımlılıkla mücadeledir. Bağımlıkla mücadelede özyeterlilik pozitif katkı sağlarken (Allsop vd., 2000, Hasking ve Oei , 2007; Lozano vd. 2006), bir başka çalışmada (Riordan vd., 2018) FoMO düzeyi yüksek olan bireylerin daha yüksek düzeyde alkol kullandıkları ve bağımlılığa daha yatkın oldukları bulgulanmıştır. Çalışma sonuçlarından da görüleceği üzere özyeterlik ve FoMO arasındaki beklenen ilişki negatiftir. Bizim çalışma bulgumuzda bu beklentiyi doğrulamaktadır.

Üniversite öğrencileri ile yapılan bu çalışmada öz yeterlilik ile FoMO arasında negatif ilişki bulgulanmıştır. Bu bağlamda özyeterlik seviyesi yüksek olan öğrencilerin daha düşük düzeyde FoMO yaşayacağı şeklinde yorumlanabilir. Ancak iki kavram arasındaki ilişkide farklı değişkenlerin modele dahil edilmesi FoMO yu etkileyen başka öncüllerin daha kapsamlı anlaşılmasına katkı sağlayacaktır. 


\title{
EXTENDED ABSTRACT
}

\section{The Effects of General Self-Efficacy on Fear of Mising Out of Faculty of Health Sciences Students}

\author{
Pinar Erdoğan - Yasemin Şanlı \\ Karamanoğlu Mehmet Bey University
}

In this study, it is aimed to find whether the general self-efficacy levels of university students have a significant effect on FoMO and if any, the effect level to be determinedand to contribute to the literature.The scope of the research in terms of application consists of 450 students studying at KaramanogluMehmetbey University, Faculty of Health Sciences.

A total of 346 usable questionnaires were obtained and the data were collected between date of 02.05.2019 and 31.05.2019. The students who agreed to participate in the study were required to have at least one social media account and smartphone. In the study, the quantitative data collection method (Yaziciogluand Erdogan, 2014, pp.9) and the correlational research model searching the relationship between variables were used as data collection methods (Gurbetoglu, 2018). The general self-efficacy scale used in the study was developed by Sherer et al. (1982), and the Turkish adaptation was made by Yildirim and Ilhan (2010). Reliability of the scale whose Turkish form consists of 17 items was found to be 0,86 by Sherer et al. (1982) and 0.80 by Yildirım and Ilhan (2010). In the scale, the questions were prepared in a five-point Likert style. In the scale, 11 questions are reverse and 6 questions are straight questions. Each question score ranged from 1 to 5, and the higher the scores, the higher the self-efficacy belief. The FoMO scale used in the study is a five-point Likert-type scale developed by Przybylski. The Turkish reliability study was conducted by Gokler et al. (2016) using a sample of 200 university students. Each item in the scale is scored between 1-5 points. As the score obtained from the scale increases, the probability of the fear of missing the developments will increase. Skies et al. (2016) found the Cronbach's alpha coefficient to be 0.81 . 
Firstly, the self-efficacy scale was examined with validity and reliability analyzes. As a result of exploratory factor analysis of the factor structure of the scale, two factors with eigenvalues above 1 were determined. The 2 factors identified explained $48.13 \%$ of the variance. The 2 -factor structure of general self-efficacy was confirmed by confirmatory factor analysis. As a result of the reliability analysis of the General Self-Efficacy Scale, the Cronbach's alpha coefficient was found to be 0.77 and our scale was found to be a reliable scale and a concordant result was found (Chen et al. 2001; Sohng et al. 2002; Lau-Walker 2004; and Kim and Omizo 2005; Yildirim and Ilhan, 2010). The FoMO scale was analyzed by validity and reliability analyzes. As a result of exploratory factor analysis of the factor structure of the scale, two factors with eigenvalues above 1 were determined. Two factors explained $62.89 \%$ of the variance. The two-factor structure of the FoMO scale was confirmed by confirmatory factor analysis. As a result of the reliability analysis of the FoMO scale, the Cronbach's alpha coefficient was found to be 0.77 , and our scale was found to be a reliable scale and a concordant result was found in the literature (Gokler et al. 2016; Aydın, 2018).

To test the hypotheses in the study and to determine whether there is a linear relationship between our independent variable self-efficacy and FoMO, when it was Pearson Correlation analysis was performed to determine the degree of this relationship. According to the findings of the research, a negative and very weak correlation was found between the selfefficacy levels and the FoMO levels of the health care faculty students $(\mathrm{r}=$ $-0,178 ; p<0.01)$. When the sub-dimensions of the self-efficacy scale and the fear of missing the developments were evaluated; it was found taht there was a negative and very weak correlation between the onset size and FoMO $(\mathrm{r}=-0.204 ; \mathrm{p}<0.01)$. When the sub-dimensions of the self-efficacy scale and the FoMO sub-dimensions were examined, a negative and weak relationship was found between the start-up level dimension and the curiosity dimension $(\mathrm{r}=-0.293 ; \mathrm{p}<0.01)$.

Multiple linear regression analysis was performed to test the linear relationships between the sub-dimensions of the self-efficacy and the subdimensions between the FoMO and its sub-dimensions, to investigate how much of the change in the FoMO and its sub-dimensions could be explained by the self-efficacy dimensions and to express the relationship 
between variables mathematically. The results of the regression analysis indicated that $082 \%$ of the changes in the curiosity dimension of FoMO were explained by the level of onset of self-efficacy sub-dimensions, that no dimension of self-efficacy had a significant effect on the importance dimension of FoMO, and that the level of self-efficacy of the subsection of FoMO was explained by the start-up level of 037\%. Multiple linear regression analysis was performed to test linear relationships between sub-dimensions of self-efficacy and sub-dimensions between FoMO and its subdimensions, to investigate how much of the change in FoMO and its subdimensions can be explained by self-efficacy dimensions, and to express the relationship between variables mathematically. Regression analysis results shows that $082 \%$ of the changes in the curiosity dimension of FoMO are explained by the start-up level of self-efficacy sub-dimensions, and that no dimension of self-efficacy has a significant effect on the importance dimension of FoMO, and $037 \%$ of the changes are explained by self-efficacy sub-dimensions.

Regression analysis results shows that $082 \%$ of the changes in the curiosity dimension of FoMO were explained by start-up level of self-efficacy sub-dimensions, that none of the dimensions of self-efficacy had a significant effect on the importance dimension of FoMO, and that the level of self-efficacy of the subsection of FoMO was explained by the start-up level of $037 \%$.

When the studies in the literature are examinedPrzybylski et al.(2013), who investigated the motivational, emotional, and behavioral correlations of FoMO, found that individuals who felt less adequate experienced fear of losing at a higher level. Again Przybylski negatively correlated FoMO with life satisfaction. While there are studies showing a positive relationship between life satisfaction and self-efficacy (Akgunduz, 2016), many studies have found a negative relationship between burnout and self-efficacy, which are the products of life dissatisfaction (Karahan and Bolat, 2011; Bolat, 2011; Çelikkaleli, 2011). While there is a negative correlation between self-efficacy and burnout, there are studies that affect each other positively between FoMO and burnout (Barber and Cucalon, 2017; Elhai et al. 2016). Another positive effect of self-efficacy is the fight against addiction. While self-efficacy contributed positively to the fight against addiction (Allsop et al., 2000, Hasking and Oei, 2007; Lozano et al., 2006), 
another study (Riordan et al., 2018) found that individuals with high FoMO levels were more likely to use alcohol and were more prone to addiction. As can be seen from the results of the study, the expected relationship between self-efficacy and FoMO is negative. Our study confirms this expectation.

In this study conducted with university students, a negative relationship was found between self-efficacy and FoMO. In this context, it was interpreted that students with higher self-efficacy levels would experience a lower level of FoMO. However, the inclusion of different variables in the relationship between the two concepts will contribute to a more comprehensive understanding of other premises that influence FoMO.

\section{Kaynakça / References}

Aşkar, P., ve Umay, A. (2001). İlköğretim matematik öğretmenliği öğrencilerinin bilgisayarla ilgili özyeterlik algısı. Hacettepe Üniversitesi Ĕ̆itim Fakültesi Dergisi, 21(21), 1-8.

Aydın, H. (2018) Sosyal Medyadaki Gelişmeleri Kaçırma Korkusunun (FoMO) İçgüdüsel Alımlara Etkisinin Öz Belirleme Kuramı İle Açıklanması. Uluslararası İktisadi ve İdari İncelemeler Dergisi,17. UíK Özel Sayis1, 415-426.

Aylar, F. ve Aksin, A. (2011). Sosyal bilgiler öğretmen adaylarının öz-yeterlilik inanç düzeyleri ve problem çözme becerileri üzerine bir araştırma:Amasya örneği. Ahi Evran Üniversitesi Kırşehir Eğitim Fakültesi Dergisi, 12(3), 299-313.

Bahar, H. H. (2019). Sınıf öğretmen adaylarında akademik öz-yeterlik algısının akademik başarıyı yordama gücü. İlköğretim Online, 18(1), 149157.

Bandura, A. (1977). Self-efficacy: Toward a unifying theory of behavioral change. Psychological Review, 84(2), 191-215.

Barber, L. K., ve Santuzzi, A. M. (2017). Telepressure and college student employment: The costs of staying connected across social contexts. Stress and Health, 33(1), 14-23.

Beyens, I., Frison, E., ve Eggermont, S. (2016). I don't want to miss a thing: Adolescents' fear of missing out and its relationship to adolescents' social needs, Facebook use, and Facebook related stress. Computers in Human Behavior, 64, 1-8. 
Błachnio, A., ve Przepiórka, A. (2018). Facebook intrusion, fear of missing out, narcissism, and life satisfaction: A cross-sectional study. Psychiatry research, 259, 514-519.

Bolat, O. İ. (2011). Öz yeterlilik ve tükenmişlik ilişkisi: lider-üye etkileşiminin aracılık etkisi. Ege Akademik Bakış Dergisi, 11(2), 255-266.

Carleton, E. L., Barling, J., and Trivisonno, M. (2018). Leaders' trait mindfulness and transformational leadership: The mediating roles of leaders' positive affect and leadership self-efficacy. Canadian Journal of Behavioural Science/Revue canadienne des sciences du comportement, 50(3), 185.

Chen G, Gully SM, Eden D ve ark. (2001) Validation of a new general selfefficacy scale. Organ Res Methods, 4(1), 62-83.

Çapık, C. (2014). Geçerlik ve güvenirlik çalışmalarında doğrulayıcı faktör analizinin kullanımı. Anadolu Hemşirelik ve Sağlık Bilimleri Dergisi, 17(3), 196-205.

Dan Herman, 2011. The fear of missing out. Fear of Missing Out. 01.07.2019 tarihinde http://FoMOfearofmissingout. com/FoMO adresinden erişilmiştir.

Dönmez, B. (2014). Pozitif psikolojik sermaye ile işe ilişkin duyuşsal iyilik algısı, iş doyumu, işgören performansı ve yaşam doyumu ilişkilerinin seyahat acentası çalışanları örnekleminde incelenmesi. Doktora Tezi, Mersin Üniversitesi, 230 Sosyal Bilimler Enstiütüsü, Mersin.

Erdoğan, P. ve İraz, R. (2019). Örgütsel vatandaşlık, örgütsel sinizm ve tükenmişliğe pozitif psikolojik sermaye etkisi. Konya:Eğitim Yayınevi.

Eroğlu, A. (2010). Çok değişkenli istatistik tekniklerinin varsayımları 231 (Ed. Ş. Kalaycı) SPSS uygulamalı çok değişkenli istatistik teknikleri, 5. Baskı. Ankara: Asil Yayın Dağıtım Ltd. Şti.

Eşitti, Ş. (2015). Bilgi çağinda problemli internet kullanimi ve enformasyon obezitesi: Problemli internet kullanımı ölçeğinin üniversite öğrencilerine uygulanmasi. İstanbul Üniversitesi İletişim Fakültesi Dergisil Istanbul University Faculty of Communication Journal, 49, 75-97.

Gökler, M. E., Aydın, R., Ünal, E., ve Metintaş, S. (2016). Sosyal ortamlarda gelişmeleri kaçırma korkusu ölçeğinin Türkçe sürümünün geçerlilik ve güvenilirliğinin değerlendirilmesi. Anadolu Psikiyatri Dergisi, 17(1), 52-59.

Gurbetoğlu, A. (2018). Bilimsel Araştırma Yöntemleri.Erişim Adresi: http://agurbetoglu.com/files/2\%20ARA \%C5\%9ETIRMA $\% 20 \%-$ 20T\%C3\%9CRLER\%C4\%B0.pdf, E.T.19.09.2019 
Gürcan, A. (2005). Bilgisayar özyeterliği algısı ile bilişsel öğrenme stratejileri arasındaki ilişki. Eurasian Journal of Educational Research (EJER), 19, 179-193.

Haşlaman, T., ve Aşkar, P. (2007). Programlama dersi ile ilgili özdüzenleyici öğrenme stratejileri ve başarı arasındaki ilişkinin incelenmesi. Hacettepe Üniversitesi Eğitim Fakültesi Dergisi, 32(32), 110-122.

Hefferon, K. ve Boniwell, I (2014). Positıve Psychology Theory, Researc And Applıcatıons. (Çeviri Editörü:Tayfun Doğan). Ankara: Nobel Akademik Yayıncilik.

https://dictionary.cambridge.org/tr/s\%C3\%B6zl\%C3\%BCk/ingilizce/FoMO E.T.15.06.2019

https://en.oxforddictionaries.com/definition/FoMO E.T.15.06.2019

https://visual.ly/community/infographic/lifestyle/FoMO-epidemic E.T.01.07.2019

https://www.guncelpsikoloji.net/arastirma-yontemleri/nicel-ve-nitel-arastirma-yontemleri-nelerdir-h6483.html E.T.02.07.2019

İslamoğlu, A.H.(2009). Sosyal Bilimlerde araştırma yöntemleri. (1.Basım) İstanbul: Beta Basım Yayım A.Ş.

Kalaycı, Ş. (2010). Faktör analizi. (Ed. Ş. Kalaycı) SPSS uygulamalı çok değişkenli istatistik teknikleri. 5. Baskı. Ankara: Asil Yayın Dağıtım Ltd. Şti

Kim, B.S.K. ve Omizo, M.M. (2005) Asian and European American cultural values, collective self-esteem, acculturative stress, cognitive flexibility, and general self efficacy among Asian American College students. J Couns Psychol, 52(3), 412-419.

Kotaman, H. (2008). Özyeterlilik inancı ve öğrenme performansının geliştirilmesine ilişkin yazın taraması. Uludağ Üniversitesi Eğitim Fakültesi Dergisi, 21(1), 111-133.

Köseoğlu, P. (2010). Biyoloji eğitiminde birleştirme tekniği temelli öğretimin akademik başarı, özyeterlik ve tutuma etkisi. Hacettepe Üniversitesi Ĕ̆itim Fakültesi Dergisi, 39(39), 244-254.

Küçüksille, E (2010). Basit doğrusal regresyon. (Ed. Ş. Kalayc1) SPSS Uygulamalı Çok Değiş̧kenli İstatistik Teknikleri. (5. Baskı) Ankara: Asil Yayın Dağıtım Ltd. Şti.

Lau-Walker M (2004) Relationship between illness representation and self-efficacy. J Adv Nurs, 48(3), 216-225. 
Maddux, J. (Ed.) (1995). Self-efficacy, adaptation, and adjustment: Theory, research, and application. New York: Plenum

Oberst, U., Wegmann, E., Stodt, B., Brand, M., ve Chamarro, A. (2017). Negative consequences from heavy social networking in adolescents: The mediating role of fear of missing out. Journal of adolescence, 55, 51-60

Ozzyirmidokuz, E. K., ve Karakas, B. A. (2019). Dijital Bağımlılık ile Mücadelede Sosyal Bilişimin Rolü . 5th International Management Information Systems Conference (IMISC 2018) (pp.90-93). Ankara, Turkey

Öztürk, İ. (2017). İşgörenin görev bağımlılı̆̆ı, politik davranışları, rol çatışması ve belirsizliğinin tükenmişlik üzerindeki etkisi: Să̆lık kurumlarında bir inceleme. Doktora Tezi, Çağ Üniversitesi. Sosyal Bilimler Enstitüsü. Mersin.

Przybylski, A. K., Murayama, K., DeHaan, C. R., ve Gladwell, V. (2013). Motivational, emotional, and behavioral correlates of fear of missing out. Computers in Human Behavior, 29(4), 1841-1848.

Reagle, J. (2015).Following the Joneses: FOMO and conspicuous sociality. http://firstmonday.org/ojs/index.php/fm /article/ view/6064/4996, E.T.18. 11. 2019.

Rogers, A. P., ve Barber, L. K. (2019). Addressing FoMO and telepressure among university students: Could a technology intervention help with social media use and sleep disruption?. Computers in Human Behavior, 93, 192-199.

Schumacker, R.E. ve Lomax, R.G. (1996). A beginner"s guide to structural equation modeling. Mahwah, New Jersey: Lawrence Erlbaum Associates, Publishers

Sherer, M., Maddux, J.E., Mercandante, B. ve ark. (1982) The self- efficacy scale: Construction and validation. Psychol Rep, 51, 663-671.

Sohng, K.Y., Sohng, S., Yeom, H.A. ve ark. (2002) Health-promoting behaviors of elderly Korean Immigrants in the United States. Public Health Nurs, 19(4), 294-300.

Stajkovic, A. D., ve Luthans, F. (1998). Self-efficacy and work-related performance: A meta-analysis. Psychological bulletin, 124(2), 240.

Sungur, O. (2010). Korelasyon analizi. (Ed. Ş. Kalaycı) SPSS Uygulamalı Çok Değişkenli İstatistik Teknikleri.(5. Baskı). Ankara: Asil Yayın Dağıtım Ltd. şti. 
Tozkoparan, S. B., ve Kuzu, A. (2019). The relationship between fear of missing out (FoMO) levels and cyberloafing behaviors of teacher candidates. Anadolu Üniversitesi Eğitim Bilimleri Enstitüsü Dergisi, 9(1), 87110.

Ulaştıran, T. (2017) Çă̆ımızın salgını fomo: Pazarlama dünyasındaki başarısının ardındaki gerçekler. 13.06.2019 tarihinde https://pazarlamasyon.com/cagimizin-salgini-FoMO-pazarlama-dunyasindaki-basarisinin-ardindaki-gercekler/ adresinden erişilmiştir.

Urgan, S ve Sevim, Ş. (2019). Uluslararası sağlık kuruluşlarında Sosyal Sermaye ve pozitif psikolojik sermaye etkileşiminde kültürel zeka. Konya:Eğitim yayınevi.

Wiesner, L. (2017). Fighting FoMO: A study on implications for solving the phenomenon of the fear of missing out. Master's thesis, University of Twente.

Yazıcıoğlu, Y. ve Erdoğan S. (2014). SPSS uygulamalı bilimsel araştırma yöntemleri. (4. Bask1) Ankara: Detay Yayınları.

Yıldırım, F., ve İlhan, İ. Ö. (2010). Genel öz yeterlilik ölçeği Türkçe formunun geçerlilik ve güvenilirlik çalışması. Türk Psikiyatri Dergisi, 21(4), 301308.

\section{Kaynakça Bilgisi / Citation Information}

Erdoğan, P. ve Şanlı, Y. (2019). Sağlık bilimleri fakültesi öğrencilerinde genel özyeterliliğin gelişmeleri kaçırma korkusu üzerine etkisi. OPUS-Uluslararası Toplum Araştırmaları Dergisi, 14(20), 594-620. DOI: 10.26466/opus.595661 